\title{
Empirical Analysis of Volatility and Co-movements in Serbian Frontier Financial Market: MGARCH Approach
}

Jelena Z. Minović*

Abstract:

This article presents an empirical calculation of volatility and co-movements for selected securities listed at the Belgrade Stock Exchange (www.belex.rs). It applied multivariate GARCH (MGARCH) models to the analysis of comovements in the Serbian frontier financial market. For the empirical work, bivariate and trivariate versions of the restricted BEKK, DVEC, and CCC models were used. Empirical results showed that MGARCH models overcome the usual concept of the time invariant correlation coefficient. Additionaly, the results show that the conditional variances and covariances between returns on the Serbian financial market exhibit significant changes over time.

Keywords: Volatility, conditional covariance, multivariate GARCH models, maximum likelihood estimation, two-step estimation.

JEL: $\mathrm{C} 1, \mathrm{C} 3, \mathrm{C} 4, \mathrm{C} 5$;

DOI: $10.2478 / \mathrm{v} 10033-010-0004-5$

\section{Introduction}

Volatility plays an important role in controlling and forecasting risks in various financial operations (Wang and Yao, 2005). I estimated the generalized autoregressive conditional heteroscedasticity (GARCH) model in order to capture the time-varying variances of my data from the Belgrade stock exchange in the univariate case (Minović, 2007a). I was then motivated to extend these models to the multivariate dimension. The goal of this article is to present an application of multivariate GARCH (MGARCH) models to the analysis of variances and covariances in the Serbian frontier financial market (Minović, 2007b). The main goal of this article is to show that MGARCH models overcome the usual concept of the time invariant correlation coefficient. It is often the case in finance that the covariance between some two series is of interest, just as the variances of the individual series themselves. While univariate descriptions of GARCH models (see Bollerslev, 1986) are useful and important, the problems of risk assessment, asset allocation, hedging in futures markets and options pricing, portfolio Value at Risk, and CAPM betas estimates require a multivariate framework (Wang and Yao, 2005). This is because all the aforementioned problems require covariances as inputs. MGARCH models specify equations for how the variances and covariances move over time. There are many examples in which empirical multivariate models of conditional heteroscedasticity can be used fruitfully. An illustrative list includes the following analysis (Tse, 2000): portfolio optimization (Kroner and Claessens, 1991), pricing of assets (Hafner and Herwartz, 1998) and derivatives, computation of the Value at Risk (Rombouts and Verbeek, 2004; Bauwens and Laurent, 2004), futures hedging (Park and Switzer, 1995; Yang and Allen, 2004; Bera et al., 1997; Lien and Luo, 1994), volatility transmitting (Karolyi, 1995) and asset allocation,

\footnotetext{
* Jelena Z. Minović

Belgrade Banking Academy, Faculty for Banking, Insurance and Finance, Union University e-mail: jelena.minovic@gmail.com; jelena.minovic@bba.edu.rs
} 
estimation systemic risk in banking (Schröder and Schüler, 2003), determination of the leverage effect (De Goeij and Marquering, 2004; Kroner and Ng, 1998), estimation of the volatility impulse response function (Hafner and Herwartz 1998, 2006; Elder, 2003), nonlinear programming (Altay-Salih, Pinar and Leyffer, 2003), hedging the currency exposure risk (Kroner and Sultan, 1991; Valiani, 2004), calculation of the minimum capital risk requirements for portfolio of assets (Brooks et al., 2002), determining misspecification tests for MGARCH models (Tse and Tsui, 1999), modeling of the changing variance structure in an exchange rate regime (Bollerslev, 1990), applying MGARCH models in the analysis of individual financial markets (Minović, 2007b).

MGARCH models used in this article are as follows: the restricted version of BEKK (named after Baba, Engle, Kraft and Kroner, initially due to Engle and Kroner, 1995), diagonal vector ARCH model (DVEC, initially due to Bollerslev, Engle and Wooldridge, 1988), and the Constant Conditional Correlation Model (CCC, by Bollerslev, 1990). For the empirical work, the restricted BEKK, DVEC, and CCC models are preferable. This is because they are much easier to estimate, while maintaining a sufficient level of generality. These models are relatively simple in comparison to the unrestricted models version, which allows one to achieve reliable estimates of variances and covariances.

The BEKK model: Engle and Kroner (1995) proposed a quadratic formulation for the parameters that ensured a positive definiteness conditional variance-covariance matrix $(t)$, which became known as the BEKK model (Brooks et al., 2003). In this model, the number of parameters grows linearly with the number of assets. Therefore, this model is relatively parsimonious and suitable for a large set of assets (De Goeij, 2004). The BEKK model is in the form:

$\sum_{t}=C_{0} C_{0}^{\prime}+\sum_{k=1}^{K} \sum_{i=1}^{q} A_{k i}^{\prime} \varepsilon_{t-i} \varepsilon_{t-i}^{\prime} A_{k i}+\sum_{k=1}^{K} \sum_{i=1}^{p} B_{k i}^{\prime} \sum_{t-i} B_{k i}$

where $C_{0}$ is a lower triangular matrix and $A_{k i}$ and $B_{k i}$ are $N \times N$ parameter matrices. Based on the symmetric parameterization of the model, $\mathrm{t}$ is almost surely positive definite provided that $C_{0} C_{0}^{\prime}$ is positive definite (Tsay, 2005). The necessary condition for the covariance stationarity of the BEKK model is having the eigenvalues, i.e. the characteristic roots of $\sum_{i=1}^{q} \sum_{k=1}^{K}\left(A_{i k}^{*} \otimes A_{i k}^{*}\right)+\sum_{i=1}^{p} \sum_{k=1}^{K}\left(B_{i k}^{*} \otimes B_{i k}^{*}\right)$ less than one in modulus. Hence, the process can still render stationary even if there exists an element with a value greater than one in the matrix. Obviously, this condition is different from the stationary condition required by the univariate GARCH model, that is, the sum of the ARCH and GARCH terms has to be less than one (Brooks, 2002).

The diagonal $\mathrm{VEC}^{1}$ (DVEC) model: Under the diagonal VEC (DVEC) model, each variance-covariance term is postulated to follow a GARCH-type equation. The model can be written as follows (Tse and Tsui, 1999, and Brooks, 2002):

$$
\sigma_{i j, t}=c_{i j}+\sum_{h=1}^{p} a_{h i j} \varepsilon_{t-h, i} \varepsilon_{t-h, j}+\sum_{h=1}^{q} b_{h i j} \sigma_{t-h, i j} \quad 1 \leq i \leq j \leq k
$$

where $c_{i j}, a_{h i j}$ and $b_{h i j}$ are parameters. The DVEC multivariate GARCH model could also be expressed as an infinite order multivariate ARCH model, where the covariance $\left(\sigma_{i j}\right)$ is expressed as a geometrically declining weighted average of past cross products of unexpected returns, with recent observations carrying higher weights.

The Constant Conditional Correlation (CCC) Model: Bollerslev (1990) suggested a multivariate GARCH model in which all conditional correlations are constant and the conditional variances are modeled by univariate GARCH models. This is the so-called Constant Conditional Correlation Model (CCC) (Tse and Tsui, 1999). Thus the $\mathrm{CCC}$ model is given by

$$
\begin{aligned}
& \sigma_{i i, t}=c_{i}+\sum_{h=1}^{p} a_{h i} \varepsilon_{t-h, i}^{2}+\sum_{h=1}^{q} b_{h i} \sigma_{t-h, i} \quad i=1, \ldots, k \\
& \sigma_{i j, t}=\rho_{i j} \sqrt{\sigma_{i i, t} \sigma_{i j, t}} \quad 1 \leq i<j \leq k
\end{aligned}
$$

$\rho_{t}=\rho=\left[\rho_{i j}\right], \rho_{i i}=1$ (Bauwens et al., 2006, and Tse, 2000),

where ${ }_{t}$ is the $N \times N$ conditional correlation matrix of ${ }_{t}$ and $t$ is symmetric with unit diagonal elements. The dynamic of the covariances $\left(\sigma_{i j}\right)$ is determined only by the dynamics of the two conditional variances $\left(\sigma_{i i}\right)$. There are $N(N-1) / 2$ parameters in (Bauwens et al., 2006).

In this article, I estimated multivariate (bivariate and trivariate) GARCH models: the restricted version of BEKK, diagonal vector $A R C H$ model (DVEC), and Constant

\footnotetext{
${ }^{1}$ VEC is the column-stacking operator.
} 
Conditional Correlation Model (CCC) for daily log returns of the BELEX15 index, Hemofarm and Energoprojekt stocks for the one year period from October 2005 to October 2006. Daily returns are measured by the logdifferences of closing prices. The analyzed stocks are listed at the Belgrade Stock Exchange (www.belex.rs). The methods for estimation parameters used are maximum log-likelihood (in BEKK and DVEC models) and a two-step approach (in CCC model). Prior to multivariate GARCH analysis, univariate GARCH analysis was performed. I used four steps in building a volatility model for each of the analyzed return series. The first step was to specify a mean equation by testing for serial dependence in the data, and building an ARMA model for the return series so as to remove any linear dependence. The second step was to use the residuals of the mean equation to test for ARCH effects. The third step was to specify a volatility model when the ARCH effects were statistically significant and perform a joint estimation of the mean and volatility equations. This allowed us to conclude that the right model for BELEX15 index is the ARMA $(1,1)-\operatorname{GARCH}(1,1)$, for Hemofarm stock is the ARMA(2,2)-IGARCH(1,1), and for Energoprojekt stock the $\operatorname{ARMA}(0,0)-\operatorname{GARCH}(1,1)$ model. Finally, in the fourth step I checked the fitted models carefully: the Ljung-Box statistics of standardized residuals and its squared values showed that the models are adequate for describing the conditional heteroscedasticity of the data. After a bivariate and trivariate conditional heteroscedasticity model had been fitted, I used the Ljung-Box statistics (Q-test) of standardized residuals, those of the squared residuals, and of the cross product of standardized residuals to check for the model's adequacy. The overall result is that MGARCH models perform well statistically.

The hypotheses are: the conditional variances of stock returns on the Serbian financial market are very unstable over time; the conditional covariances between returns for the both stocks and the index on the Serbian financial market exhibit significant changes over time.

The rest of the paper is organized as follows. At the beginning of the second section I present data, and analyze its stationarity. The rest of Section 2 presents ARIMA processes, and univariate GARCH analysis. At the beginning of the third section I present the results of empirical calculation for bivariate version BEKK, DVEC and CCC models for log returns of BELEX15 index and Hemofarm stock. Then I discuss the final results (variances and covariances plots) of the empirical calculation for bivariate version models mentioned above but now for log returns of the BELEX15 index and Energoprojekt stock. The rest of Section 3 presents the empirical results of the trivariate version of BEKK, DVEC and CCC models. Section 4 concludes the paper. Appendix A presents tables and graphs used for the analysis.

\section{Results of Estimation of Univariate GARCH Models}

\subsection{Data and Descriptive Statistics}

BELEX15 tracks free float capitalization of the 15 most liquid, continuously traded stocks. The maximum weight for each component is limited to $20 \%$. BELEX15 is calculated and published both with intraday and closing values. The index base period is October 1, 2005, and the base value was $1,000.00$ index points (http://www.sinteza.net/). BELEX15 is not adjusted for paid dividends, and is not protected from the dilution effect that appears as a result of the dividends' payout (http://www.belex.rs).

"Hemofarm Concern" is the biggest pharmaceutical company in Serbia. We observe from Figure 2.1 that in
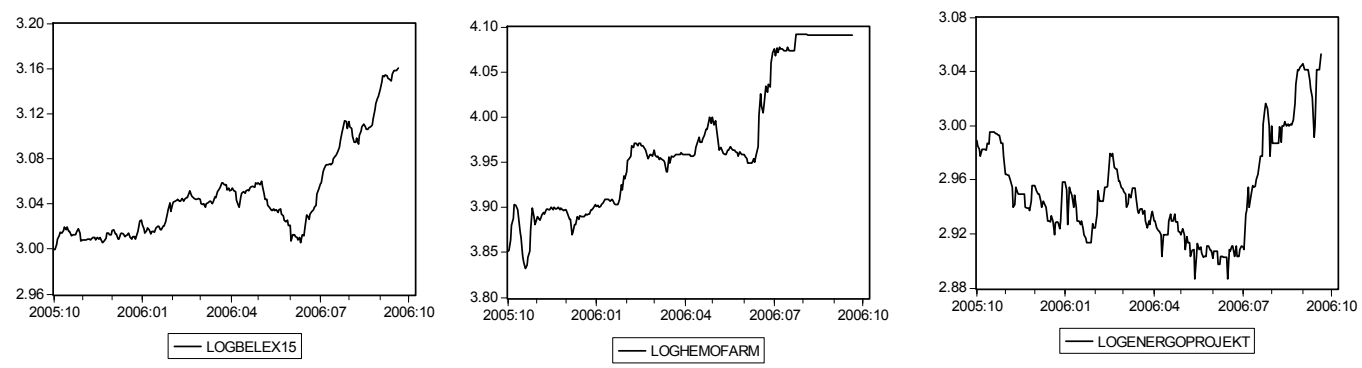

Figure 2.1: The data graph for log BELEX15 index, log Hemofarm stock and log Energoprojekt stock, respectively. 


\begin{tabular}{|c|c|c|c|c|}
\hline Series & ADF Test & level & Critical Value & $\mathrm{H}_{0}$ \\
\hline $\log$ BELEX15 & -0.32 & $5 \%$ & -3.43 & can not be rejected \\
\hline dlog(BELEX15) & -13.28 & $5 \%$ & -3.43 & rejected \\
\hline log Hemofarm & -1.98 & $5 \%$ & -3.43 & can not be rejected \\
\hline dlog(Hemofarm) & -12.73 & $5 \%$ & -3.43 & rejected \\
\hline log Energoprojekt & -1.22 & $5 \%$ & -3.43 & can not be rejected \\
\hline dlog(Energoprojekt) & -17.16 & $5 \%$ & -3.43 & rejected \\
\hline
\end{tabular}

Table 2.1: The results of testing for a unit root for BELEX15 index, Hemofarm and Energoprojekt stocks. The null hypothesis $\mathrm{H}_{0}$ : unit root exists in the process; The alternative hypothesis: the process is stationary.
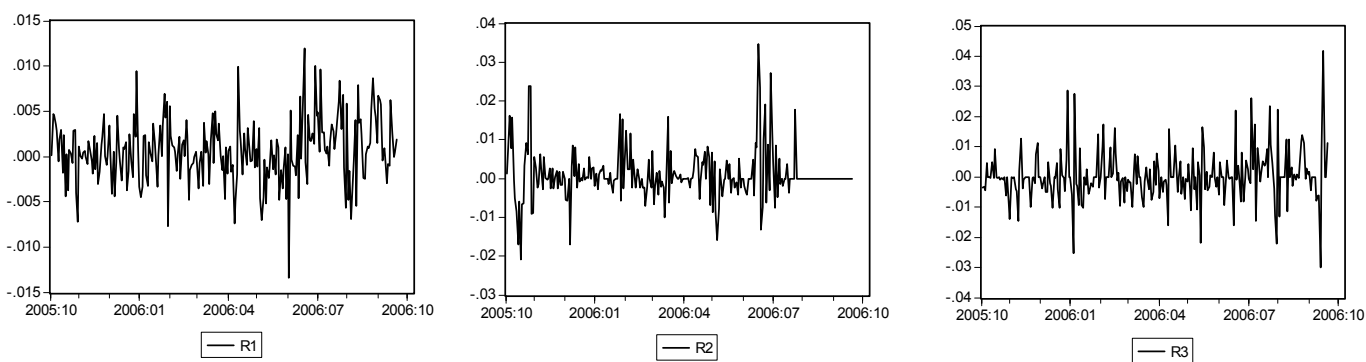

Figure 2.2: The graphs of daily log returns of the BELEX15 index $\left(r_{1}\right)$, Hemofarm $\left(r_{2}\right)$ and Energoprojekt $\left(r_{3}\right)$ stocks, respectively.

July 2006 the price of Hemofarm stock rapidly grew. This happened because German Schtada Company bought $67 \%$ stocks of Hemofarm. After that, the price curve is flat, which means that the price of Hemofarm stocks was not changing.

The "Energoprojekt" company is one of the most important firms in Serbia in the construction industry. The company got a contract in Nigeria valued at 151 million Euros in February 2006. We see that as the first peak of the price jump on Figure 2.1. After that, the price again goes down until July 2006, when positive business results raise investment in Energoprojekt stock, with a constant positive price trend from then on. Possible reasons for this are the previous underpricing of Energoprojekt's fundamentals compared to similar companies in the Balkan region and the entrance of new funds to the Belgrade Stock Exchange without a broad offer of high quality stocks. Additionally, management of "Energoprojekt" was focused on activities which supported its stock price.

Now, I test the stationarity of my series. This will be done by testing for the presence of a unit root using the Augmented Dickey Fuller test (ADF). The results of testing for a unit root are presented in Table 2.1. Now, I test if log BELEX15 index, log Hemofarm and log Energoprojekt, and its first difference (log return) are stationary.
From the table above we can see that the Augmented Dickey-Fuller test statistic for log BELEX15, log Hemofarm, and log Energoprojekt series are greater than the -3.43 critical value, so we conclude that the null hypothesis of a unit root presence cannot be rejected. I proceed with unit root testing for the first difference. An ADF test of log return for the BELEX15 index, log return for Hemofarm, and log return for Energoprojekt stocks are smaller than the critical value -3.43 , so we infer that the null hypothesis of an existing unit root should be rejected and the alternative hypothesis of stationarity cannot be rejected. Thus, series log BELEX15 index, log Hemofarm, and log Energoprojekt stocks have one unit root, hence their first differences (log returns) are stationary. For this reason, it is the usual practice to work with the logs of the changes (i.e. the first differences) of a series rather than the series itself. Let $r_{1 t}$ be the log return series of the BELEX15 index, $r_{2 t}$ the log return series of Hemofarm stock and $r_{3 t}$ the log return series of Energoprojekt stock. On Figure 2.2 we plot the daily log returns of my series.

We observe in Figure 2.2 that the log returns of BELEX15 index, Hemofarm and Energoprojekt stocks offer evidence of the well known volatility clustering effect. It is a tendency for volatility in financial markets to appear in bunches. Large returns (of either sign) are expected to follow large returns, and small returns (of either sign) to 


\begin{tabular}{c|ccccccccc} 
Series & Mean & Max & Min & $\begin{array}{c}\text { Std. } \\
\text { Dev. }\end{array}$ & Skewness & Kurtosis & JB & Prob & Obs \\
\hline $\log$ BELEX15 & 3.05 & 3.16 & 3.00 & 0.04 & 1.22 & 3.69 & 68.05 & 0.00 & 252 \\
$\log$ Hemofarm & 3.97 & 4.09 & 3.83 & 0.08 & 0.45 & 2.01 & 18.72 & 0.00 & 252 \\
$\log$ Energoprojekt & 2.95 & 3.05 & 2.89 & 0.04 & 0.75 & 2.88 & 23.96 & 0.00 & 252 \\
$\mathbf{r}_{1}$ & 0.00 & 0.01 & -0.01 & 0.00 & 0.03 & 4.22 & 15.58 & 0.00 & 252 \\
$\mathbf{r}_{2}$ & 0.00 & 0.03 & -0.02 & 0.01 & 1.29 & 8.59 & 398.00 & 0.00 & 252 \\
$\mathbf{r}_{3}$ & 0.00 & 0.04 & -0.03 & 0.01 & 0.74 & 7.20 & 207.83 & 0.00 & 252
\end{tabular}

Table 2.2: Descriptive statistics of log BELEX15, log Hemofarm and log Energoprojekt series and their first differences (log return series), where $r_{1}$ is log return for the BELEX15 index and $r_{2}$ is log return for Hemofarm stock, and $r_{3}$ is log return for Energoprojekt stock.

\begin{tabular}{|c|c|c|c|c|c|c|c|c|c|c|c|c|}
\hline & \multicolumn{4}{|c|}{ BELEX15 } & \multicolumn{4}{|c|}{ Hemofarm } & \multicolumn{4}{|c|}{ Energoprojekt } \\
\hline Variable & Coeff. & S.E. & t-Stat & Prob. & Coeff. & S.E. & t-Stat & Prob. & Coeff. & S.E. & t-Stat & Prob. \\
\hline C & 0.0006 & 0.0004 & 1.6265 & 0.1051 & 0.0008 & 0.0004 & 1.9726 & 0.0497 & 0.0003 & 0.0005 & 0.4853 & 0.6279 \\
\hline AR(1) & 0.7851 & 0.1254 & 6.2597 & 0.0000 & 1.6347 & 0.0270 & 60.4803 & 0.0000 & - & - & - & - \\
\hline $\operatorname{AR}(2)$ & - & - & - & - & -0.8903 & 0.0317 & -28.0701 & 0.0000 & - & - & - & - \\
\hline MA(1) & -0.6385 & 0.1562 & -4.0870 & 0.0001 & -1.6229 & 0.0397 & -40.8643 & 0.0000 & - & - & - & - \\
\hline MA(2) & - & - & - & - & 0.8971 & 0.0416 & 21.5816 & 0.0000 & - & - & - & - \\
\hline AIC & \multicolumn{4}{|l|}{-8.5342} & \multicolumn{4}{|l|}{-7.3657} & \multicolumn{4}{|l|}{-6.7493} \\
\hline SIC & \multicolumn{4}{|c|}{-8.4921} & \multicolumn{4}{|c|}{-7.2952} & \multicolumn{4}{|c|}{-6.7353} \\
\hline F-Stat & \multirow{2}{*}{\multicolumn{4}{|c|}{$8.0886(0.0004)$}} & \multirow{2}{*}{\multicolumn{4}{|c|}{$10.7233(0.0000)$}} & \multicolumn{4}{|c|}{ D-W stat $=2.1405$} \\
\hline JB & 18.8513 & $0.0001)$ & & & & & & & 207.829 & $5(0.0000)$ & & \\
\hline
\end{tabular}

Table 2.3: Estimate mean equation for log return of the BELEX15 index, Hemofarm and Energoprojekt stocks.

follow small returns (Brooks, 2002). Additionaly, the observed cluster in each series tend to occur simultaneously. This motivates an application of a bivariate and trivariate GARCH model (Franke et al., 2005).

I tested my distributions of log series and of log returns against normal distribution, using descriptive statistics (Table 2.2). Each series has positive skewness which means that these distributions have a long right tail. The kurtosis for each series of log returns exceeds 3 , so the distributions of these series are peaked (leptokurtic) relative to the normal. Hence, the kurtosis of log Hemofarm and log Energoprojekt stocks is less than 3; these distributions are flat (platykurtic) relative to the normal. We found that the values of Jarque-Bera normality tests are very high and probabilities are significantly low for each series of log returns so the null hypothesis of a normal distribution should be rejected. Thus, each of these series is not normally distributed.

\subsection{ARIMA Analysis}

Considering the correlograms, I will try to estimate the correct model for log returns. It can be deduced that, for log return of the BELEX15 index, the first two, and fifth autocorrelation coefficients, and the first two partial autocorrelation coefficients, are significant. In the case of log return for Hemofarm, the first and seventh autocorrelation coefficients and the first, sixth, and seventh partial autocorrelation coefficients are significant. But, considering the correlogram for Energoprojekt stock, I observed that there are no autocorrelation and partial autocorrelation coefficients that are significant, and the Ljung-Box test statistics is insignificant, as well (see Minović, 2007c).

Here, I perform an Autoregressive Moving Average (ARMA) analysis for the log returns in order to obtain a residual series which is free of serial correlation. I specify and estimate ARMA models which minimize the information criteria.

In Table 2.3, I report coefficients, standard errors, tStatistics, probabilities, Akaike's and Schwartz's Criteria, FStatistics and the Jarque-Bera (JB) normality test. The standard errors and associated t-values reported in this thesis are calculated using the quasi-maximum likelihood methods of Bollerslev and Wooldridge (1992), i.e. the standard errors are robust to the density function underlying the residuals (Baur, 2004).

Considering the correlogram of the data, I have tested several combination $\operatorname{ARMA}(p, q)$. With the probabilities pretty low and Akaike (AIC) and Schwarz (SIC) criteria the 


\begin{tabular}{|c|c|c|c|c|c|c|c|c|c|c|}
\hline \multicolumn{9}{|c|}{ The Ljung-Box Statistics } & \multicolumn{2}{|c|}{$A R C H-L M(5)$ test } \\
\hline series & $Q(2)$ & $Q(5)$ & $\mathbf{Q}(9)$ & $Q(36)$ & $Q^{2}(2)$ & $Q^{2}(5)$ & $Q^{2}(9)$ & $Q^{2}(36)$ & F-stat & Obs*R^2 \\
\hline BELEX15 & $\begin{array}{c}0.655 \\
(0.721)\end{array}$ & $\begin{array}{c}2.780 \\
(0.734)\end{array}$ & $\begin{array}{c}4.290 \\
(0.891)\end{array}$ & $\begin{array}{l}26.559 \\
(0.874)\end{array}$ & $\begin{array}{c}2.726 \\
(0.256)\end{array}$ & $\begin{array}{c}4.121 \\
(0.532)\end{array}$ & $\begin{array}{c}6.496 \\
(0.689)\end{array}$ & $\begin{array}{l}26.178 \\
(0.885)\end{array}$ & $\begin{array}{c}0.726 \\
(0.604)\end{array}$ & $\begin{array}{c}3.666 \\
(0.598)\end{array}$ \\
\hline Hemofarm & $\begin{array}{c}1.453 \\
(0.484)\end{array}$ & $\begin{array}{c}7.483 \\
(0.187)\end{array}$ & $\begin{array}{l}11.491 \\
(0.244)\end{array}$ & $\begin{array}{l}34.857 \\
(0.523)\end{array}$ & $\begin{array}{l}33.866 \\
(0.000)\end{array}$ & $\begin{array}{l}47.446 \\
(0.000)\end{array}$ & $\begin{array}{l}72.915 \\
(0.000)\end{array}$ & $\begin{array}{l}86.635 \\
(0.000)\end{array}$ & $\begin{array}{c}6.613 \\
(0.000)\end{array}$ & $\begin{array}{l}29.775 \\
(0.000)\end{array}$ \\
\hline Energoprojekt & $\begin{array}{c}1.848 \\
(0.397)\end{array}$ & $\begin{array}{c}2.209 \\
(0.820)\end{array}$ & $\begin{array}{c}3.406 \\
(0.946)\end{array}$ & $\begin{array}{l}26.659 \\
(0.871)\end{array}$ & $\begin{array}{l}10.437 \\
(0.005)\end{array}$ & $\begin{array}{l}13.065 \\
(0.023)\end{array}$ & $\begin{array}{l}13.852 \\
(0.128)\end{array}$ & $\begin{array}{l}26.716 \\
(0.870)\end{array}$ & $\begin{array}{c}3.138 \\
(0.009)\end{array}$ & $\begin{array}{l}15.099 \\
(0.010)\end{array}$ \\
\hline
\end{tabular}

Table 2.4: The Ljung-Box statistics of standardized residuals and squared standardized residuals in ARMA models and tests for ARCH effect.

best for ARMA $(1,1)$ (all the other tested models showed much poorer performance) process, I conclude that the right model for log BELEX15 index is ARIMA(1,1,1). Akaike's criterion suggest the $\operatorname{ARMA}(6,6)$ model, and Schwarz's criterion suggest the $\operatorname{ARMA}(2,2)$ model for log return of Hemofarm stock. SIC correctly identifies an ARMA model, whereas AIC tends to over fit the model (Altay-Salih, 2003). Then, according to SIC criterion I chose the $\operatorname{ARMA}(2,2)$ process for log return of Hemofarm stock. I then concluded that the right model for log Hemofarm stock is ARIMA(2,1,2). For Energoprojekt stock, not one autocorrelation and partial autocorrelation functions are significant and the Ljung-Box test statistics is never significant. I found that $\operatorname{ARMA}(0,0)$ is the most suitable, i.e. the right model for log return of Energoprojekt stock is the white noise process. I then concluded that the right model for the series of log Energoprojekt stock is $\operatorname{ARIMA}(0,1,0)$.

The residuals obtained from the ARMA models for each series are not normally distributed (Table 2.3), because the normality assumption is rejected at the $5 \%$ significance level if JB>5.99 (Vogelvang, 2005). However, even if the distribution of the residuals is not normal, the estimates are still consistent under quasi-maximum likelihood (QML) assumptions (EViews 5 User's Guide, 2005). Obviously, the residuals have to be tested for the absence of autocorrelation. With the Ljung-Box (Q) test, I tested whether the residuals behave like a white noise process (Vogelvang, 2005). Table 2.4 reports the $\mathrm{Q}(\mathrm{m})$ and $\mathrm{Q}^{2}(m)$ statistics for each series.

It is evident from the table above that the Q-statistics for squared residuals across all lag lengths are significant for Hemofarm stock and we infer the presence of ARCH effects. The Q-statistics for squared residuals across all lag lengths for BELEX15 index are not significant and ignore the existence of ARCH effects. But the heteroscedasticity in BELEX15, Hemofarm, and Energoprojekt is also observed in the plots of the actual values of residuals. From Table 2.4 we see that is only one significant autocorrelation on lag 2 in squared residuals in the ARMA model for Energoprojekt stock. It is evident an $\mathrm{ARCH}$ effect exists for Energoprojekt stock. On the other hand, the Lagrange multiplier (LM) test (Table 2.4) shows strong ARCH effects for Hemofarm stock with the test statistic $F$ $=6.613$, the $p$-value of which is zero; and an ARCH effect for Energoprojekt stock with test statistic $F=3.138$, the $p$ value 0.009 . This test then shows no $A R C H$ effect for the BELEX15 index with test statistic $\mathrm{F}=0.726$ and $p$-value 0.604 .

\subsection{Univariate GARCH Models}

Although the ARCH model is simple, it often requires many parameters to adequately describe the volatility process of an asset return. For instance, consider the daily log return of Hemofarm stock. An ARCH(10) model is needed for the volatility process according to partial autocorrelation functions (see Minović, 2007c). Some alternative models must be sought (Tsay, 2005). According to the partial autocorrelation function I found that an $\mathrm{ARCH}(2)$ model is needed for the volatility process of Energoprojekt stock. For the BELEX15 it is then possible not to have an ARCH component but a GARCH one. The $\mathrm{GARCH}$ is more general, i.e. $\operatorname{GARCH}(p, 0)=\mathrm{ARCH}(p)$.

The detected presence of $A R C H$ effects necessitates the use of a more dynamic and flexible GARCH specification to explicitly model the conditional variance and covariance of residuals (Vogelvang, 2005). GARCH is more general and better than the ARCH process, so I proceeded with the estimation of the GARCH (volatility) model (estimated parameters are in Table A1 in AppendixA).

From Table A1 in Appendix A it is evident that coefficients for ARMA processes are highly significant except constant coefficients which are insignificant for BELEX15 and Hemofarm. Thus, the results for BELEX15 show that all coefficients in the variance equation are positive and statistically significant at the $10 \%$ level. BELEX15 satisfies the GARCH $(1,1)$ model. 

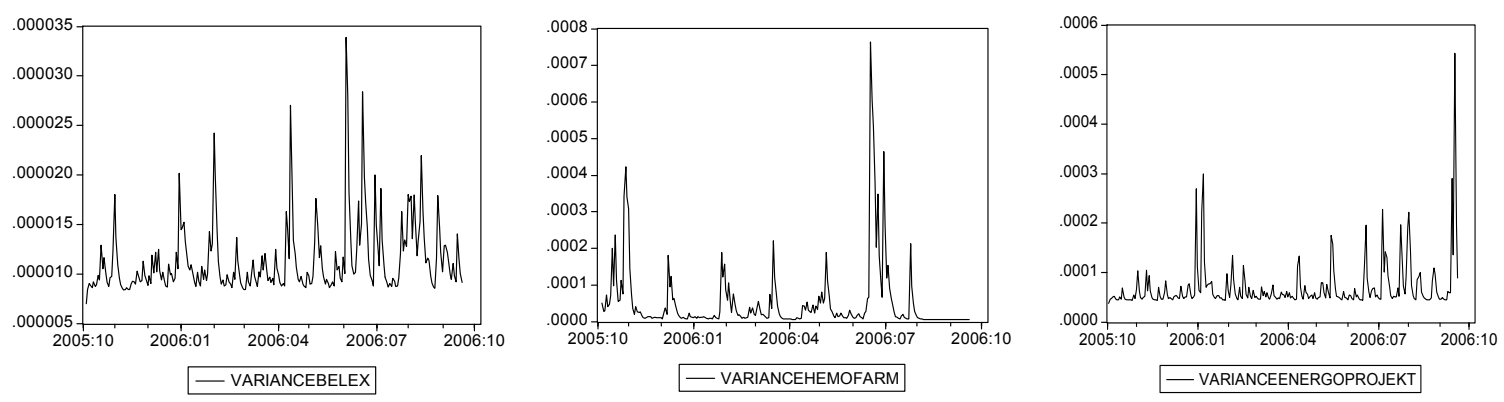

Figure 2.3 plots the GARCH variance series for the BELEX15 index, Hemofarm, and Energoprojekt stocks.

A joint estimation of the ARMA $(1,1)-\operatorname{GARCH}(1,1)$ model for BELEX15 gives

$$
\begin{aligned}
& r_{t}=\underset{(0.1050)}{0.8207} r_{t-1}-\underset{(0.1376)}{0.6918} \varepsilon_{t-1}+\varepsilon_{t}, \\
& \hat{\sigma}_{t}^{2}=\underset{\left(2.14 \cdot 10^{-6}\right)}{4.06 \cdot 10^{-6}}+\underset{(0.0700)}{0.1446} \varepsilon_{t-1}^{2}+\underset{(0.2226)}{0.5030} \sigma_{t-1}^{2} .
\end{aligned}
$$

From the volatility equation (BELEX15), the implied unconditional variance of $\varepsilon_{t}$ is

$$
\frac{4.06 \cdot 10^{-6}}{1-0.1446-0.5030}=1.1521 \cdot 10^{-5} \text {. This value is the same }
$$

as $S . E^{2}{ }^{2}=(0.003395)^{2}=1.1526 \cdot 10^{-5}$. This confirms the adequacy of the $\operatorname{GARCH}(1,1)$ model.

The results in Table $A 1$ for Hemofarm show that all coefficients are statistically significant, with the sum of GARCH parameters close to unity, for example $a_{i i}+b_{i i} \approx 1$. This suggests the persistence of $\mathrm{ARCH}$ effects in the datasets and, hence, implies that the current information remains important for forecasts of conditional variances at all horizons (Yang and David, 2004). This special type of GARCH model is termed as Integrated GARCH (IGARCH). In order to examine the IGARCH process, I applied the Wald test. First, I formulated the null hypothesis: the sum of the ARCH and GARCH coefficients is very close to one. According to the results of the Wald test $(F=0.249, p=0.618 ; p>5 \%)$ the null hypothesis was not rejected. Hence, I conclude that log returns of Hemofarm follow the IGARCH process.

A joint estimation of the $\operatorname{ARMA}(2,2)-\operatorname{IGARCH}(1,1)$ model for Hemofarm gives

$r_{t}=\underset{(0.1964)}{1.0251} r_{t-1}-\underset{(0.1289)}{0.3326} r_{t-2}-\underset{(0.1749)}{0.9907} \varepsilon_{t-1}+\underset{(0.0992)}{0.4318} \varepsilon_{t-2}+\varepsilon_{t}$

$\hat{\sigma}_{t}^{2}=\underset{\left(1.61 \cdot 10^{-6}\right)}{3.45 \cdot 10^{-6}}+\underset{(0.2644)}{0.6632} \varepsilon_{t-1}^{2}+\underset{(0.0970)}{0.4351} \sigma_{t-1}^{2}$.

From Table A1 for Energoprojekt we see that the constant term in the mean equation is not significant, the constant term in the variance equation is significant the $10 \%$ level, the ARCH term is significant at $5 \%$ and the $\mathrm{GARCH}$ term is not significant.

A joint estimation of the $\operatorname{ARMA}(0,0)-\operatorname{GARCH}(1,1)$ model for Energoprojekt gives

$r_{t}=\varepsilon_{t}$ (white noise process),

$\hat{\sigma}_{t}^{2}=\underset{\left(1.60 \cdot 10^{-5}\right)}{3.10 \cdot 10^{-5}}+\underset{(0.1066)}{0.2691} \varepsilon_{t-1}^{2}+\underset{(0.2503)}{0.2985} \sigma_{t-1}^{2}$.

Although the GARCH term is insignificant, I decided to include it, because with the GARCH model I eliminate autocorrelation at lag 2 in the correlogram of squared residuals which was shown by the $\mathrm{ARCH}(1)$ model. We know that $\operatorname{GARCH}(1,1)$ is equal to $\operatorname{ARCH}(\infty)$ and because of that it removes autocorrelation. I have tested several combinations of $\operatorname{GARCH}(p, q)$ models such as $\operatorname{ARCH}(2), \operatorname{GARCH}(2,1)$, and $\operatorname{GARCH}(1,2)$. Each model was inconsistent, i.e. I found that $\operatorname{GARCH}(1,1)$ is the most suitable one.

Thus, the BELEX15 index follows the $\operatorname{ARMA}(1,1)$ $\operatorname{GARCH}(1,1)$ model, Hemofarm stock follows the $\operatorname{ARMA}(2,2)-\operatorname{IGARCH}(1,1)$ model, and Energoprojekt stock follows the ARMA $(0,0)-\operatorname{GARCH}(1,1)$ model. The fitted models can be checked by using the standardized residual and its squared process. The Ljung-Box statistics (Table A2 in Appendix A) of standardized residuals and those of its squared show that the models are adequate for describing the heteroscedasticity of the data.

I applied the ARCH test on the standardized residuals to see if there are any $A R C H$ effects left. Both the Fstatistic and the LM-statistic are very insignificant, suggesting no ARCH effect up to order 5 or 10 for each series, the BELEX15 index, Hemofarm, and Energoprojekt stocks (Table A2 in Appendix A).

In addition to visual inspection, Figure 2.3 tells us that the GARCH variance series exhibits significant changes over time for both stocks and index. Therefore, these 


\begin{tabular}{|c|c|c|c|c|c|c|c|c|c|}
\hline & \multicolumn{3}{|c|}{ BEKK } & \multicolumn{3}{|c|}{ DVEC } & \multicolumn{3}{|c|}{$\mathrm{CCC}$} \\
\hline$M U(1)$ & -0.0003 & 0.0003 & -0.8476 & -0.0001 & 0.0002 & -0.2762 & -0.0002 & 0.0002 & -0.6594 \\
\hline OMEGA(1) & 0.0008 & 0.0006 & 1.2669 & 0.0000 & 0.0000 & 1.3918 & 0.0000 & 0.0000 & 1.3900 \\
\hline BETA(1) & 0.9665 & 0.0404 & 23.9362 & 0.5044 & 0.2825 & 1.7854 & 0.4300 & 0.3335 & 1.2891 \\
\hline ALPHA(1) & 0.1888 & 0.0558 & 3.3810 & 0.1356 & 0.0770 & 1.7606 & 0.1583 & 0.0994 & 1.5919 \\
\hline ALPHA(2) & 0.7468 & 0.0429 & 17.3895 & 0.5775 & 0.0560 & 10.3148 & 0.5761 & 0.0498 & 11.5765 \\
\hline OMEGA(3) & 0.0000 & 0.5845 & 0.0000 & 0.0000 & 0.0000 & -0.8696 & - & - & - \\
\hline BETA(3) & - & - & - & 0.5980 & 0.1394 & 4.2893 & - & - & - \\
\hline ALPHA(3) & - & - & - & 0.2798 & 0.0830 & 3.3711 & - & - & - \\
\hline \multicolumn{2}{|c|}{ Log likehood } & \multicolumn{2}{|c|}{2076.330} & \multicolumn{3}{|c|}{1915.184} & \multicolumn{3}{|c|}{2470.535} \\
\hline \multicolumn{2}{|c|}{$\mathrm{HQC}$} & \multicolumn{2}{|c|}{-16.6207} & \multicolumn{3}{|c|}{-15.2936} & \multicolumn{3}{|c|}{-19.8135} \\
\hline
\end{tabular}

Table 3.1 reports the coefficients, standard errors, z-statistics, log-likelihood and information criteria for restricted bivariate BEKK, DVEC, and CCC models. The standard errors represent the variance-covariance matrix of the maximum likelihood estimates of the model coefficients.

variances are very unstable over time. A plot of GARCH variances of the BELEX15 index, Hemofarm and Energoprojekt stocks reveals that the BELEX15 index has been more volatile than Hemofarm and Energoprojekt stocks. Thus, the hypothesis about instability of the conditional variances of returns on the Serbian market cannot be rejected.

\section{Multivariate GARCH (MGARCH) Models}

For the multivariate application I start with the bivariate case. In the first part of this section I use data of daily log returns for the BELEX15 index and Hemofarm stock, and in the second part I use data of daily log returns for the BELEX15 index and Energoprojekt stock. The data set covers the period from October 3, 2005 to October 6, 2006. For both univariate and multivariate (bivariate and trivariate) GARCH models, the unknown model parameters are estimated using the Berndt-HallHall-Hausman (BHHH) algorithm². Additionally, EViews 4.1 does not support estimation of MGARCH models, so I extended EViews with new subprograms. This required utilization of informatical methods (programming). Although, the new version of Eviews (6.0) supports multivariate GARCH modeling through regular program menus and commands, manually writing a program gives

\footnotetext{
2 This algorithm uses the first derivatives of the quasi-maximum likelihood (QML) with respect to the number of parameters that are contained in multivariate GARCH models. This is an iterative procedure; The $\mathrm{BHHH}$ algorithm needs suitable initial parameters (Brooks et al., 2003).
}

us more freedom and flexibility. For all calculations in my programs for bivariate and trivariate versions, the number of iteration is 100 and convergence criterion is $1 \cdot 10^{-5}$ which ought to be considered a procedure with high precision.

\subsection{Bivariate GARCH Models (BELEX15 and Hemofarm)}

For the parameter estimation I use the maximumlikelihood approach in the BEKK model as well as in the bivariate DVEC model. The estimation of multivariate GARCH models is commonly done by maximizing a Gaussian likelihood function. Even if it is unrealistic in practice, the normality assumption may be justified by the fact that the Gaussian quasi-maximum likelihood (QML) estimator is consistent provided the conditional mean and the conditional variance are specified correctly (Brooks, 2002). For the parameter estimation in the CCC model I use the first step (a mean and volatility part) of a two-step approach (the second step is the correlation part). The two-step estimation approach has been developed to increase computational efficiency, and has apparently been used more often in practice (Wang and Yao, 2005).

Using estimated parameters from Table 3.1, we obtain the mean equations of the $\operatorname{BEKK}(1,1)$ model:

$$
\begin{aligned}
& r_{1 t}=\varepsilon_{1 t}, \\
& r_{2 t}=\underset{(0.0001)}{-0.0006+\varepsilon_{2 t},}
\end{aligned}
$$


BEKK
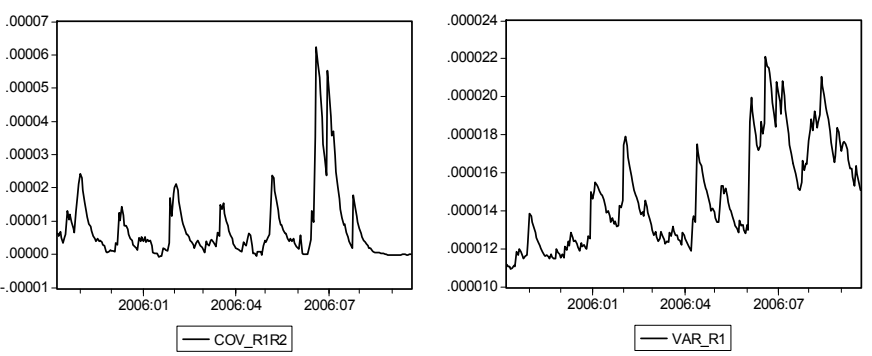

DVEC
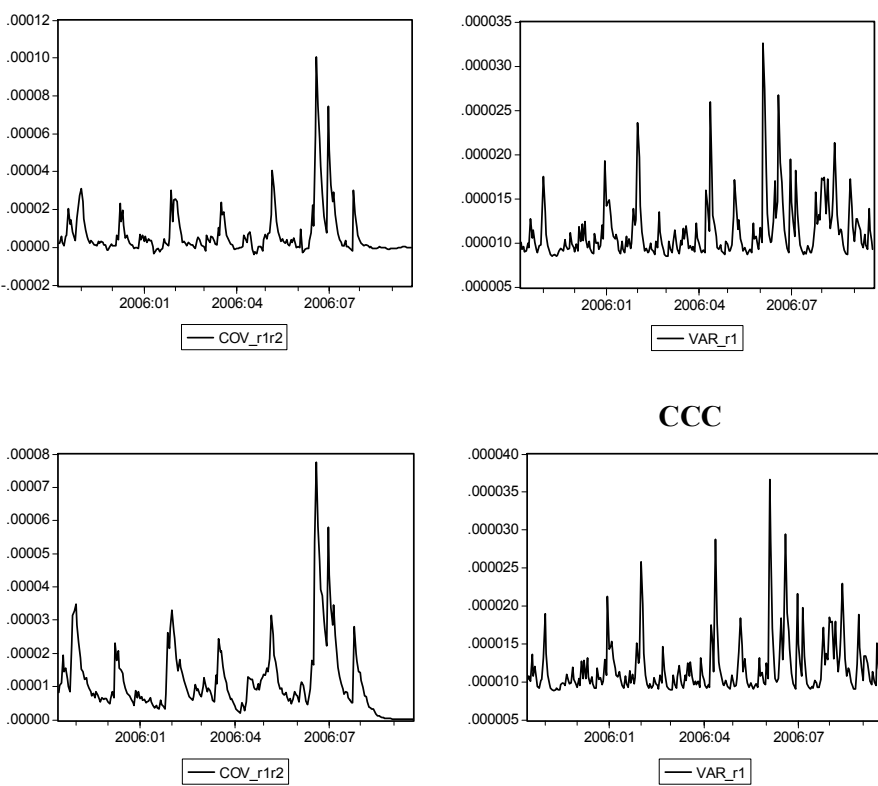
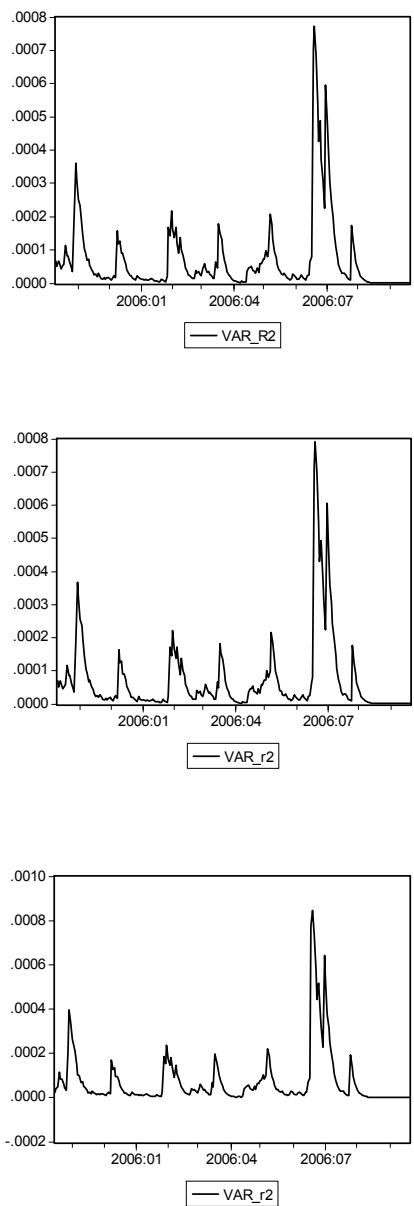

Figure 3.1: Estimated conditional covariance and variances of daily log returns for the BELEX15 index and Hemofarm stock in the restricted BEKK, DVEC, and CCC models, respectively.

where ${ }_{t}$ is the shock, or innovation, of the series at time $t$. The mean equation of the BELEX15 index satisfies a white noise process. Standard error terms are reported in the parentheses. In the DVEC model the estimated parameters $\operatorname{OMEGA}(1), \operatorname{OMEGA}(2)$ and $\operatorname{OMEGA}(3)$ are insignificant, and in the CCC model the estimated parameters OMEGA(1) and OMEGA(2) are insignificant. Now, I present volatility equations for the restricted BEKK, DVEC, and CCC models, respectively.

The restricted bivariate BEKK model is in the form:

$$
\begin{aligned}
& \hat{\sigma}_{11, t}=\underset{(0.0006)}{0.0008^{2}}+\underset{(0.0558)}{0.1888^{2}} \varepsilon_{1, t-1}^{2}+\underset{(0.0404)}{0.9665^{2}} \sigma_{11, t-1,} \text { (3.3) } \\
& \hat{\sigma}_{21, t}=\underset{(0.0558 \cdot 0.0429)}{0.1888 \cdot 0.7468} \varepsilon_{1, t-1} \varepsilon_{2, t-1}+\underset{(0.0404 \cdot 0.0073)}{0.9665 \cdot 0.8452} \sigma_{21, t-1,}
\end{aligned}
$$

$\hat{\sigma}_{22, t}=\underset{(0.0429)}{0.7468^{2}} \varepsilon_{2, t-1}^{2}+\underset{(0.0073)}{0.8452^{2}} \sigma_{22, t-1}$.
Where $\sigma_{11, t}, \sigma_{33, t}$ are time-varying variances of log returns on the BELEX15 index and Hemofarm stock, respectively. Then, $\sigma_{21, t}$ is covariance between log returns of the BELEX15 index and Hemofarm stock. Although in the equations above the sum of the ARCH and GARCH terms is greater than one, this fact does not matter, because the stationary condition in multivariate cases is different than the stationary condition in the univariate case.

Using the parameters from Table 3.1, we obtain the mean equations of the $\operatorname{DVEC}(1,1)$ model:

$$
\begin{aligned}
& r_{1 t}=\varepsilon_{1 t}, \\
& r_{2 t}=-\underset{(0.0001)}{0.0005+\varepsilon_{2 t},}
\end{aligned}
$$

The volatility equations are:

$$
\begin{aligned}
& \hat{\sigma}_{11, t}=\underset{(0.0770)}{0.1356} \varepsilon_{1, t-1}^{2}+\underset{(0.2825)}{0.5044} \sigma_{11, t-1}, \\
& \hat{\sigma}_{21, t}=\underset{(0.0830)}{0.2798} \varepsilon_{1, t-1} \varepsilon_{2, t-1}+\underset{(0.1394)}{0.5980} \sigma_{21, t-1},
\end{aligned}
$$




$$
\hat{\sigma}_{22, t}=\underset{(0.0560)}{0.5775} \varepsilon_{2, t-1}^{2}+\underset{(0.0123)}{0.7091} \sigma_{22, t-1} \text {, }
$$

Again, in equation (3.10) the sum of the ARCH and GARCH terms is greater than one, the condition of stationarity is not broken. This is the bivariate case and the condition of stationarity is not the same as in the univariate case.

Using the parameters from Table 3.1, we obtain the mean equations of the $\operatorname{CCC}(1,1)$ model:

$$
\begin{aligned}
& r_{1 t}=\varepsilon_{1 t}, \\
& r_{2 t}=\underset{(0.0002)}{-0.0006+\varepsilon_{2 t},}
\end{aligned}
$$

The fitted volatility model is:

$$
\begin{aligned}
& \hat{\sigma}_{11, t}=\underset{(0.0994)}{0.1583 \varepsilon_{1, t-1}^{2}}+\underset{(0.3335)}{0.4300} \sigma_{11, t-1}, \\
& \hat{\sigma}_{21, t}=\rho \sqrt{\sigma_{11, t} \sigma_{22, t}}, \quad \rho=0.4917, \\
& \hat{\sigma}_{22, t}=\underset{(0.0498)}{0.5761 \varepsilon_{2, t-1}^{2}}+\underset{(0.0113)}{0.7095} \sigma_{22, t-1} .
\end{aligned}
$$

The correlation coefficient between log return for the BELEX15 index and log return for Hemofarm stock is $\rho$. We observe that this CCC model reduces to two univariate $\operatorname{GARCH}(1,1)$ models. In this case, the two volatility processes are not dynamically related.

\subsection{Analysis of the results}

In the multivariate case I propose to examine the standardized residuals, squared standardized residuals as well as the cross products of the standardized residuals. My results show that the residual-based diagnostics provide a useful check for model adequacy (Tse, 2002).

The standardized residuals for log return of the BELEX15 index and log return of Hemofarm stock are calculated as:

$$
\begin{aligned}
& \hat{z}_{1}=\left(r_{1}-\hat{\mu}_{1}\right) / \sqrt{\sigma_{11}}, \\
& \hat{z}_{2}=\left(r_{2}-\hat{\mu}_{2}\right) / \sqrt{\sigma_{22}} .
\end{aligned}
$$

The cross product of residuals for log return of the BELEX15 index and log return of Hemofarm stock are

\begin{tabular}{|c|c|c|c|}
\hline$Q(36)$ & BELEX15 & Hemofarm & $\begin{array}{c}\text { Cross } \\
\text { product of } \\
\text { res }\end{array}$ \\
\hline $\operatorname{BEKK}(1,1)$ & $27.767(0.835)$ & $44.024(0.168)$ & - \\
\hline $\operatorname{DVEC}(1,1)$ & $22.098(0.967)$ & $49.318(0.069)$ & - \\
\hline $\operatorname{ccc}(1,1)$ & $23.158(0.952)$ & $49.509(0.066)$ & - \\
\hline \multicolumn{4}{|l|}{$Q^{2}(36)$} \\
\hline $\operatorname{BEKK}(1,1)$ & $30.973(0.706)$ & $59.588(0.008)$ & $\begin{array}{l}34.877 \\
(0.522)\end{array}$ \\
\hline $\operatorname{DVEC}(1,1)$ & $24.612(0.925)$ & $84.041(0.000)$ & $\begin{array}{l}31.903 \\
(0.664)\end{array}$ \\
\hline $\operatorname{CcC}(1,1)$ & $26.172(0.886)$ & $57.897(0.012)$ & - \\
\hline
\end{tabular}
calculated as:

$$
\hat{z}_{1} \hat{z}_{2}=\left(r_{1}-\hat{\mu}_{1}\right)\left(r_{2}-\hat{\mu}_{2}\right) / \sqrt{\sigma_{11} \sigma_{22}} \text {. }
$$

If the model is correctly specified, the standardized residuals should not be correlated, and identically distributed random variables with mean zero and variance one (EViews 5 User's Guide, 2005).
Table 3.2: The Ljung-Box statistics for the standardized residual series, squared standardized residual series and cross product of standardized residuals for log return of BELEX15 index and log return of Hemofarm stock, where the number in parentheses denotes $p$-value.

The values of Q-statistics with high $p$-values of the squared standardized residual series for log return on the BELEX15 index imply that there are no ARCH effects. Therefore, the Q-statistics and significantly low (less than 10\%) $p$-values of the squared standardized residual series for log return on Hemofarm stock imply that we have autocorrelation. It is an expected result because in the univariate case Hemofarm satisfies the IGARCH process, indicating that volatility shocks are quite persistent (EViews 5 User's Guide, 2005).

The Q-statistics for the cross product of standardized residual series and very high $p$-values (grater than 10\%) suggest no $\mathrm{ARCH}$ effects in the covariance equation (i.e. we don't have autocorrelation) for log returns of the BELEX15 index and Hemofarm stock in the BEKK and DVEC models. The covariance equation in the CCC model does not contain terms with the cross product of residuals.

The goodness-of-fit of a multivariate GARCH model can also be assessed by calling the generic plot function on a fitted "mgarch" object. There is significant deviation in the tails from the normal QQ-line for both residuals (Figure 3.2). Thus it seems that the normality assumption for the residuals may not be appropriate (Zivot and Wang, 2006). 

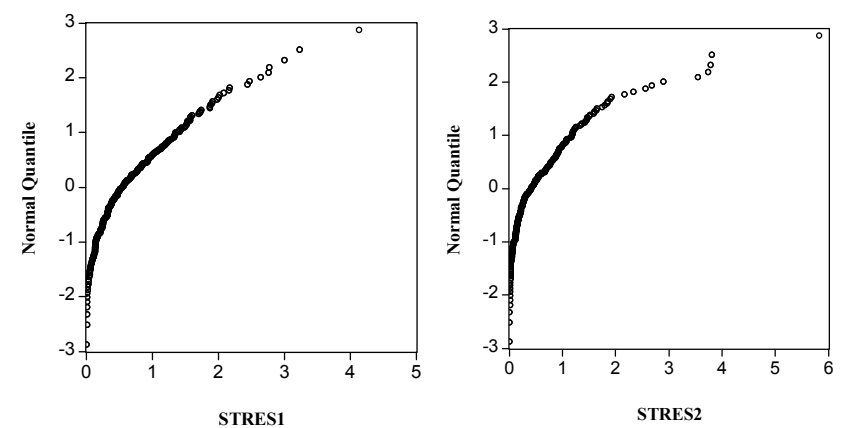

Figure 3.2: The QQ-plot of standardized residuals of the BELEX15 index (stres1) and Hemofarm stock (stres2) plotted against normal distribution in MGARCH models.

As mentioned before, the estimates are still consistent under the quasi-maximum likelihood (QML) assumptions, if the distribution of the residuals is not normal. In addition to visual inspection of the plots, Figure 3.1 tell us that the BEKK, DVEC, and CCC give results that are similar in covariances and variances. A plot of the GARCH volatilities of the BELEX15 index and Hemofarm stock reveals that the BELEX15 index is more volatile than Hemofarm stock. From figures for covariances it is evident that correlation between log returns for the BELEX15 index and Hemofarm stock is very unstable over time. We observe the greatest peak in the period of June-July 2006, when the company Schtada bought stocks of Hemofarm. In all the figures that show plotted covariances as well as all those with variances of daily log returns of Hemofarm stock we can see significant autocorrelation. This is because Hemofarm, in the univariate case, follows the IGARCH process. In fact, the changes in the conditional variances are modelled quite well.

The restricted BEKK model has seven free parameters, while the DVEC model has nine free parameters. Indeed, the restricted BEKK model is nested within the DVEC model. The CCC model and the restricted BEKK model are non-nested within each other. Although the CCC model has a smaller number of parameters than the BEKK and DVEC models, it is not nested within these two models (Tse and Tsui, 1999).

Comparing the likelihood values for the different models with a differing number of parameters may not be fair. Therefore, to make a fair comparison, I use the Akaike Information Criterion (AIC, Akaike 1973), Schwartz Information Criterion (SIC, Schwartz 1978) and HannanQuinn Criterion (HQC), which are standard tests of comparison between GARCH models in the literature (Altay-Salih, 2003). SIC is strongly consistent (but inefficient) and AIC is not consistent, but is generally more efficient. In other words, SIC will asymptotically deliver the correct model order, while AIC will deliver on average too large a model, even with an infinite amount of data. On the other hand, the average variation in the selected model orders from different samples within a given population will be grater in the context of SIC than AIC. Overall, then, no criterion is definitely superior to others (Brooks, 2002). The smaller the statistic, the better the model fit (Altay-Salih, 2003).

Based on the AIC, SIC and HQC tests (Table 3.1), we can say that $\mathrm{CCC}(1,1)$ performs better than both $\operatorname{DVEC}(1,1)$ and $\operatorname{BEKK}(1,1)$ specifications, although all three provide a solution to the same multivariate $\mathrm{GARCH}$ estimation problem. Furthermore, the BEKK model seems to do better than the DVEC representation, based on all three information criteria.

However, according to z-statistics on Table 3.1 I cannot say that the CCC model outperforms the BEKK and DVEC. Based on these statistics I cannot choose the most convenient model. Thus, Information Criteria (AIC, SIC, and $\mathrm{HQC}$ ) are not appropriate criteria for choosing a model with the best performance in the multivariate case. In other words, these tests cannot be used for comparison between multivariate GARCH models.

To sum up, it can be said that the above presented model classes are promising, and estimation does work even for moderate dimensions $N$. Especially the models for $N=2$ show good results and may be general enough. In general, I can say that these analyzed models yield good results.

\subsection{Bivariate GARCH Models (BELEX15 and Energoprojekt)}

Here, a similar procedure was repeated, but now for the BELEX15 index and Energoprojekt stock. For detailed results see the references (Minović, 2007b). Here I present only the final graphs of my calculation and modeling.

If we compare figures for conditional variances among the above presented model we will conclude that the BEKK, DVEC, and CCC give results that are similar in variances. These figures show that the BELEX15 index has always been more volatile than Energoprojekt stock. Therefore, if we compare figures for conditional covariances we will see that the BEKK, DVEC, and CCC give results that have different covariances. We observe from all the figures of covariances and from figures of Energoprojekt's variances that the first pick were in January-February 2006, when the Energoprojekt company signed a significant contract in Nigeria. 
BEKK model
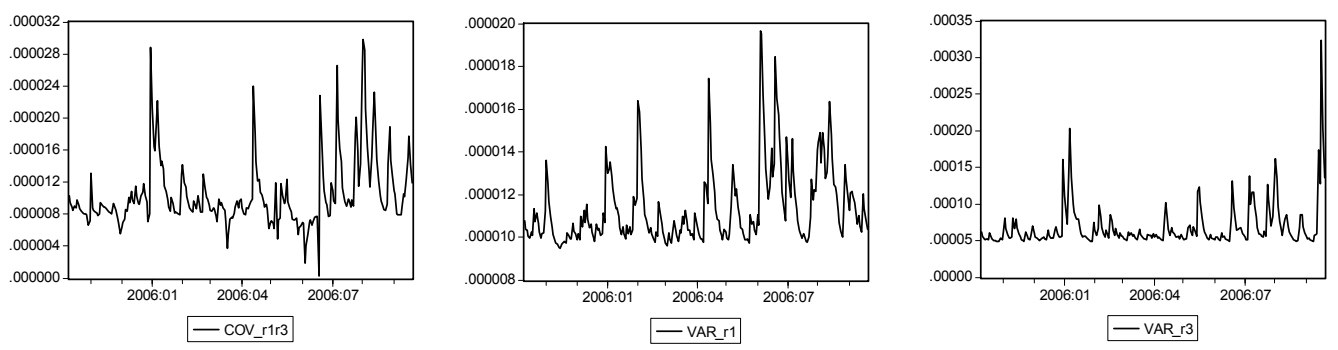

DVEC model
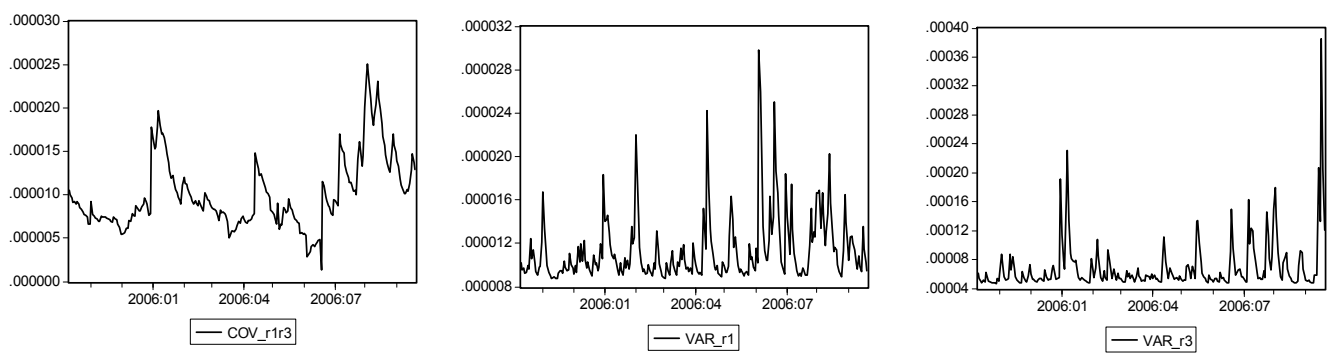

CCC model
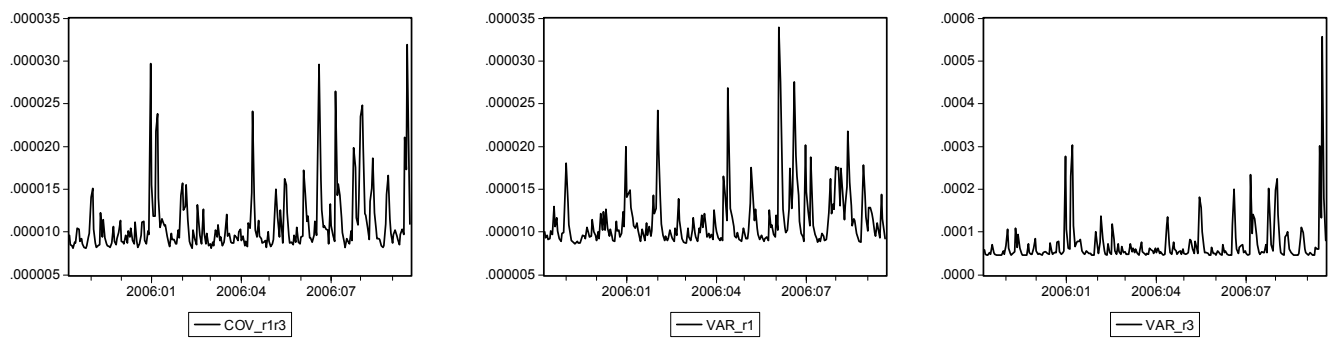

Figure 3.3: Estimated conditional covariance and variances of daily log returns for the BELEX15 index and Energoprojkt stock in the restricted BEKK, DVEC and CCC models, respectively.

Additionally, it is evident that correlation between log returns for the BELEX15 index and Energoprojekt stock is very unstable during that time.

\subsection{Trivariate Case}

In this part we consider trivariate GARCH models, and we use the data of daily log returns for the BELEX15 index, Hemofarm stock and Energoprojekt stock, respectively. I used a program for modeling the restricted version of the trivariate BEKK model, and I extended this program on the trivariate case of the DVEC and CCC models.

I found that the correlation coefficients (only the first measure of correlation) between log returns of the BELEX15 index and Hemofarm stock is 0.49 ; that between log returns of the BELEX15 index and Energoprojekt stock is 0.40; and that between log returns of Hemofarm and Energoprojekt stocks is about 0.02 . This means that these two stocks are not correlated. Let $r_{1 t}, r_{2 t}$, and $r_{3 t}$ be the log return series corrected for autocorrelation in the mean of the BELEX15 index, Hemofarm, and Energoprojekt stocks, respectively.

The methods for estimation parameters used are maximum log-likelihood and the two-step approach. Although the maximum log-likelihood method can be used for all three models (BEKK, DVEC and CCC), for CCC representation we estimate parameters using the first step of the two-step approach. It is enough because the CCC model uses a constant correlation coefficient, and the second step should be used only when the correlation coefficient is time dependent.

However, in order to choose the best model, diagnostic tests should be calculated. For diagnostic checking I used the Ljung-Box statistics of standardized residuals and those of its squared, and of the cross product of standardized residuals (Table 3.4 and 3.5). We observe that in the trivariate case we have an $\mathrm{ARCH}$ effect 


\begin{tabular}{|c|c|c|c|c|c|c|c|c|c|}
\hline & \multicolumn{3}{|c|}{ BEKK } & \multicolumn{3}{|c|}{ DVEC } & \multicolumn{3}{|c|}{ CCC } \\
\hline & Coeff. & S.E. & z-Stat & Coeff. & S.E. & z-Stat & Coeff. & S.E. & z-Stat \\
\hline$M U(1)$ & -0.0003 & 0.0002 & -1.4536 & -0.0001 & 0.0002 & -0.3216 & -0.0001 & 0.0002 & -0.6120 \\
\hline$M U(2)$ & -0.0006 & 0.0001 & -8.1946 & -0.0003 & 0.0002 & -1.6585 & -0.0006 & 0.0001 & -8.4620 \\
\hline MU(3) & -0.0005 & 0.0007 & -0.7305 & -0.0003 & 0.0006 & -0.5244 & -0.0003 & 0.0006 & -0.5453 \\
\hline OMEGA(1) & 0.0017 & 0.0004 & 4.8070 & 0.0000 & 0.0000 & 1.9624 & 0.0000 & 0.0000 & 1.3449 \\
\hline BETA(1) & 0.7826 & 0.0879 & 8.9069 & 0.5216 & 0.1549 & 3.3679 & 0.4973 & 0.3058 & 1.6260 \\
\hline ALPHA(1) & 0.3495 & 0.0739 & 4.7325 & 0.2006 & 0.0709 & 2.8288 & 0.1479 & 0.0913 & 1.6192 \\
\hline OMEGA(2) & 0.0000 & 0.0000 & 0.0519 & 0.0000 & 0.0000 & 3.0426 & 0.0000 & 0.0000 & -9.3533 \\
\hline BETA(2) & 0.8416 & 0.0058 & 144.5231 & 0.6827 & 0.0168 & 40.5688 & 0.7085 & 0.0010 & 70.8697 \\
\hline ALPHA(2) & 0.7682 & 0.0373 & 20.6101 & 0.5952 & 0.0623 & 9.5593 & 0.5820 & 0.0534 & 10.8965 \\
\hline OMEGA(3) & 0.0016 & 0.0006 & 2.4940 & 0.0000 & 0.0000 & 2.6601 & 0.0000 & 0.0000 & 5.1316 \\
\hline BETA(3) & 0.6814 & 0.1607 & 4.2397 & 0.3052 & 0.2135 & 1.4291 & 0.2269 & 0.1382 & 1.6417 \\
\hline ALPHA(3) & 0.4283 & 0.0975 & 4.3925 & 0.2479 & 0.1152 & 2.1518 & 0.2539 & 0.1057 & 2.4011 \\
\hline OMEGA(4) & 0.0001 & 0.0002 & 0.2752 & 0.0000 & 0.0000 & 5.6805 & - & - & - \\
\hline BETA(4) & - & - & - & 0.6431 & 0.0690 & 9.3175 & - & - & - \\
\hline ALPHA(4) & - & - & - & 0.2545 & 0.0692 & 3.6794 & - & - & - \\
\hline OMEGA(5) & -0.0055 & 0.0210 & -0.2643 & 0.0000 & 0.0000 & 2.2551 & - & - & - \\
\hline BETA(5) & - & - & - & 0.3899 & 0.2062 & 1.8905 & - & - & - \\
\hline ALPHA(5) & - & - & - & 0.1765 & 0.0716 & 2.4647 & - & - & - \\
\hline OMEGA(6) & 0.0003 & 0.3462 & 0.0010 & 0.0000 & 0.0000 & -0.1434 & - & - & - \\
\hline BETA(6) & - & - & - & 0.4663 & 0.2539 & 1.8363 & - & - & - \\
\hline ALPHA(6) & - & - & - & 0.3630 & 0.1137 & 3.1918 & - & - & - \\
\hline \multicolumn{2}{|c|}{ Log likehood } & \multicolumn{2}{|c|}{2886.269} & \multicolumn{3}{|c|}{2697.955} & \multicolumn{3}{|c|}{3534.373} \\
\hline \multicolumn{2}{|c|}{ Avg. log likelihood } & \multicolumn{2}{|c|}{11.8290} & \multicolumn{3}{|c|}{11.5792} & \multicolumn{3}{|c|}{14.4851} \\
\hline \multicolumn{2}{|c|}{ Number of coeff. } & \multicolumn{2}{|c|}{15} & \multicolumn{3}{|c|}{21} & \multicolumn{3}{|c|}{12} \\
\hline
\end{tabular}

Table 3.3 contains the coefficients, standard errors, z-statistics, log-likelihood, and information criteria for trivariate BEKK, DVEC and CCC models.

\begin{tabular}{c|c|c|c} 
Q(36) & BELEX15 & Hemofarm & Energoprojekt \\
\hline BEKK & $25.628(0.900)$ & $44.451(0.158)$ & $31.161(0.698)$ \\
DVEC & $23.205(0.951)$ & $43.256(0.189)$ & $34.341(0.548)$ \\
CCC & $22.976(0.955)$ & $40.311(0.247)$ & $26.675(0.871)$ \\
Q $^{2}(36)$ & & & $38.323(0.365)$ \\
BEKK & $29.221(0.781)$ & $58.530(0.010)$ & $40.719(0.270)$ \\
DVEC & $24.128(0.935)$ & $47.444(0.096)$ & $34.328(0.548)$ \\
CCC & $26.468(0.877)$ & $83.197(0.000)$ & \\
\hline
\end{tabular}

Table 3.4: The Ljung-Box statistics of standardized residuals and those of its squared for log return of the BELEX15 index, log return of Hemofarm and log return of Energoprojekt stocks, where the number in parentheses denotes $p$-value.

\begin{tabular}{c|c|c|c}
$\mathbf{Q}^{2}(\mathbf{3 6 )}$ & BELEX15-Hemofarm & BELEX15-Energoprojekt & Hemofarm- Energoprojekt \\
\hline BEKK & $30.429(0.730)$ & $32.122(0.654)$ & $34.498(0.540)$ \\
DVEC & $31.550(0.680)$ & $27.746(0.836)$ & $32.244(0.648)$
\end{tabular}

Table 3.5: The Ljung-Box statistics of cross product of standardized residuals, where the number in parentheses denotes $p$-value.

in variance equation of Hemofarm stock, except for the DVEC model. The Q-statistics for checking whether there are any ARCH effects left in the residuals show that autocorrelation is not significant in variance equations for log returns of the BELEX15 index and Energoprojekt stock.
From Table 3.4 it is evident that there are no $\mathrm{ARCH}$ effects in covariance equations for the BEKK and DVEC models for pairs BELEX15-Hemofarm; BELEX15Energoprojekt, and Hemofarm-Energoprojekt. Thus, checks of the models show that they are appropriate: Qstatistics show that the models are adequate for describing the conditional heteroscedasticity of the data. 
It is important to note that the DVEC model would be the most appropriate model, because only that one does not show the ARCH effect for the Hemofarm stock. The BEKK and CCC models have a smaller number of parameters and they are much easier to estimate than the DVEC model. Thus, the most 'complicated' model proved to be the best model.

The graphs of conditional variances (Figure $A 2$ in Appendix A) for daily log returns of the BELEX15 index, Hemofram and Energoprojekt stocks in our three considered models are very similar to graphs in the bivariate case, and even in the univariate case. All variances in all three models are highly unstable. Also, the graphs of conditional covariances (Figure A1 in Appendix A) between chosen securities are very similar to graphs in the bivariate case. It is evident that correlations between log returns of stocks and index are very unstable over time. Thus, the hypothesis about instability of the conditional covariances between returns on the Serbian financial market cannot be rejected. In Figure A1, the restricted BEKK and DVEC give results that are similar for all pair log returns of stocks and index, but those of the CCC model are very different, with covariance being positive and not of a negligible magnitude, especially in the case of Hemofarm and Energoprojekt stocks. In Figure A1 we observe that Hemofram and Energoprojekt stocks are uncorrelated; this plots around zero on the graph.

\section{Conclusion}

This article presents an empirical calculation of multivariate GARCH models (BEKK, DVEC, and CCC) in bivariate and trivariate versions, on the Serbian financial market. Detail econometric time-series analysis via ARIMA-GARCH modeling, and via MGARCH modeling is presented. I illustrated my approach by applying it to daily returns of the BELEX15 index, Hemofarm, and Energoprojekt stocks. I showed that even DVEC, CCC, and restricted version of $B E K K$ models with a reduced number of parameters give results that are accurate to an acceptable degree. All analyzed models (BEKK, DVEC, and CCC) show similar behavior in variances and covariances. The overall result is that models perform well statistically. Empirical results showed that MGARCH models overcome the usual concept of the time invariant correlation coefficient. Additionaly, the results indicate that the conditional variances and covariances between returns on the Serbian financial market exhibit significant changes over time.
Future research should examine the impact of the world financial crises on the volatility of stock prices, and co-movements between stock returns in Serbia.

\section{Acknowledgement}

The author wishes to thank Professor Zorica Mladenović from the Faculty of Economics, University of Belgrade for valuable comments. Many thanks also to Miloš Milovanović from the Faculty of Organizational Sciences, University of Belgrade, and to Mrdjan Mladjan, from University Pompeu Fabra in Barcelona, who offered valuable advice on the content and the English of this paper. All remaining errors are mine alone. $\boldsymbol{E}$.

\section{References}

Altay-Salih, A., Pinar M., Leyffer S. 2003. "Constrained Nonlinear Programming for Volatility Estimation with GARCH Models". http://www.siam.org/journals/sirev/45-3/40011.html

Baur, D. 2004. "A Flexible Dynamic Correlation Model". Working Paper. http://papers.ssrn.com/sol3/papers.cfm?abstract_id=377722

Bauwens, L., Laurent S. and Rombouts J. V. K. 2006. "Multivariate GARCH models: A Survey". Journal of Applied Econometrics: 79-109

Bollerslev, T. 1986. "Generalized Autoregressive Conditional Heteroskedasticity", Journal of Econometrics 31: 307-327.

Bollerslev T., R.F. Engle, and J.M. Wooldridge. 1988. "A Capital Asset Pricing Model with Time-Varying Covariances", Journal of Political Economy 96 (1): 116-131.

Brooks, C. 2002. Introductory Econometrics for Finance. Cambridge University Press

Brooks, C., Burke S., Persand G. 2003. "Multivariate GARCH Models: Software Choice and Estimation Issues". Journal of Applied Econometrics 18: 725-234.

De Goeij, P., Marquering W. 2004. "Modeling the Conditional Covariance Between Stock and Bond Returns: A Multivariate GARCH Approach". Journal of Financial Econometrics 2 (4): 531-564

Franke, J., Härdle W., Hafner C. 2005. Introduction to Statistics of Financial Markets.

http://www.quantlet.com/mdstat/scripts/sfe/html/sfeframe131.html

Minović, J. Z. 2007a. "Univariate GARCH models: theoretical survey and application", BALCOR 07, Proceedings of International Conference, Zlatibor, Serbia.

Minović, J. 2007b. "Application of multivariate GARCH models in Serbian financial market analysis", Proceedings of International Conference, International Scientific Conference, Faculty of Economics, Belgrade, Serbia.

Minović J. Z. 2007c. "Multivariate GARCH models: Theoretical Survey and Model Application", M.Sc. Thesis. University of Belgrade, Faculty of Economics, Belgrade, Serbia.

Tsay, R. S. 2005. Analysis of Financial Time Series, Wiley, New Jersey.

Tse, Y.K. 2000. "A test for constant correlations in a multivariate GARCH model". Journal of Econometrics 98: 107-127.

Tse, Y. K. 2002. "Residual-based diagnostics for conditional heteroscedasticity models". Econometrics Journal 5: 358-373.

Tse, Y. K., and Tsui A. K. C. 1999. "A note on diagnosing multivariate conditional heteroscedasticity models". Journal of time series analysis 20 (6): 679-691.

Vogelvang, B. 2005. Econometrics: Theory and Applications with EViews. Prentice Hall. 
Wang, M. and Yao Q. 2005. "Modelling multivariate volatilities: An ad hoc method". http://stats.Ise.ac.uk/q.yao/qyao.links/paper/wy04.pdf

Yang, W., David E. A. 2004. "Multivariate GARCH hedge ratios and hedging effectiveness in Australian futures market". Accounting and Finance 45: 301-321.

Zivot, E. and Wang J. 2006. Modelling Financial Time Series with S-
PLUS. Springer.

Quantitative Micro Software. 2005. EViews 5 User's Guide

Official the Belgrade stock exchange web site, http://www.belex.rs/index-e.php

Brokerage web site, http://www.sinteza.net/

\section{Appendix A}

\section{A.1. Univariate case}

\begin{tabular}{|c|c|c|c|c|c|c|c|c|c|c|c|c|}
\hline & \multicolumn{4}{|c|}{ BELEX15 } & \multicolumn{4}{|c|}{ Hemofarm } & \multicolumn{4}{|c|}{ Energoprojekt } \\
\hline \multicolumn{13}{|c|}{ Mean Equation } \\
\hline & Coeff. & S.E. & z-Stat & Prob. & Coeff. & S.E. & z-Stat & Prob. & Coeff. & S.E. & z-Stat & Prob. \\
\hline $\mathbf{C}$ & 0.0004 & 0.0003 & 1.2485 & 0.2118 & 0.0003 & 0.0003 & 1.0360 & 0.3002 & $\begin{array}{c}-3.59 \mathrm{E}- \\
05\end{array}$ & 0.0004 & $\begin{array}{c}- \\
0.0852\end{array}$ & 0.9321 \\
\hline $\operatorname{AR}(1)$ & 0.8207 & 0.1050 & 7.8197 & 0.0000 & 1.0251 & 0.1964 & 5.2189 & 0.0000 & - & - & - & - \\
\hline $\operatorname{AR}(2)$ & - & - & - & - & $\begin{array}{c}- \\
0.3326\end{array}$ & 0.1289 & $\begin{array}{c}- \\
2.5797\end{array}$ & 0.0099 & - & - & - & - \\
\hline MA(1) & $\begin{array}{c}- \\
0.6918\end{array}$ & 0.1376 & $\begin{array}{c}- \\
5.0265\end{array}$ & 0.0000 & $\begin{array}{c}- \\
0.9907\end{array}$ & 0.1749 & $\begin{array}{c}- \\
5.6630\end{array}$ & 0.0000 & - & - & - & - \\
\hline MA(2) & - & - & - & - & 0.4318 & 0.0992 & 4.3539 & 0.0000 & - & - & - & - \\
\hline \multicolumn{13}{|c|}{ Variance Equation } \\
\hline $\mathbf{C}$ & $\begin{array}{c}4.06 \mathrm{E}- \\
06\end{array}$ & $\begin{array}{c}2.14 \mathrm{E}- \\
06\end{array}$ & 1.8971 & 0.0578 & $\begin{array}{c}3.45 \mathrm{E}- \\
06\end{array}$ & $\begin{array}{c}1.61 \mathrm{E}- \\
06\end{array}$ & 2.1436 & 0.0321 & $\begin{array}{c}3.10 \mathrm{E}- \\
05\end{array}$ & $\begin{array}{c}1.60 \mathrm{E}- \\
05\end{array}$ & 1.9376 & 0.0527 \\
\hline $\mathrm{ARCH}(1)$ & 0.1446 & 0.0700 & 2.0644 & 0.0390 & 0.6632 & 0.2644 & 2.5086 & 0.0121 & 0.2691 & 0.1065 & 2.5243 & 0.0116 \\
\hline GARCH(1) & 0.5030 & 0.2226 & 2.2597 & 0.0238 & 0.4351 & 0.0970 & 4.4873 & 0.0000 & 0.2985 & 0.2503 & 1.1926 & 0.2330 \\
\hline \multirow{5}{*}{\multicolumn{2}{|c|}{$\begin{array}{l}\text { R-squared } \\
\text { Adjusted R-squared } \\
\text { S.E. of regression } \\
\text { Sum squared resid } \\
\text { Mean dependent } \\
\text { var }\end{array}$}} & \multicolumn{3}{|c|}{0.060127} & \multicolumn{4}{|c|}{0.057546} & \multicolumn{4}{|c|}{-0.001224} \\
\hline & & \multicolumn{3}{|c|}{0.040945} & \multicolumn{4}{|c|}{0.030285} & \multicolumn{4}{|c|}{-0.013335} \\
\hline & & & 0.003395 & & \multicolumn{4}{|c|}{0.006381} & \multicolumn{4}{|c|}{0.008321} \\
\hline & & & 0.002825 & & \multicolumn{4}{|c|}{0.009853} & \multicolumn{4}{|c|}{0.017173} \\
\hline & & & 0.000641 & & \multicolumn{4}{|c|}{0.000912} & \multicolumn{4}{|c|}{0.000253} \\
\hline
\end{tabular}

Table A1: A joint estimation of the mean and volatility equations.

\begin{tabular}{l|cc|cc|cc} 
& \multicolumn{2}{|c|}{ The Ljung-Box Statistics } & \multicolumn{2}{c|}{ ARCH-LM(5) test } & \multicolumn{2}{c}{$A R C H$-LM(10) test } \\
\hline \multicolumn{1}{|c|}{ series } & $\mathbf{Q}(\mathbf{3 6})$ & $\mathbf{Q}^{\mathbf{2}(36)}$ & F-stat & Obs*R^2 $^{*}$ & F-stat & Obs*R^2 \\
BELEX15 & $25.590(0.901)$ & $26.319(0.881)$ & $0.265(0.932)$ & $1.351(0.930)$ & $0.423(0.934)$ & $4.356(0.930)$ \\
Hemofarm & $29.038(0.788)$ & $23.685(0.943)$ & $0.084(0.995)$ & $0.432(0.994)$ & $0.146(0.999)$ & $1.518(0.999)$ \\
Energoprojekt & $26.447(0.878)$ & $22.156(0.966)$ & $0.799(0.551)$ & $4.028(0.545)$ & $0.606(0.808)$ & $6.183(0.800)$
\end{tabular}

Table A2: The Ljung-Box statistics and ARCH-LM test of order 5 and 10. 


\section{A. 3. Bivariate case: BELEX15-Energoprojekt}

\begin{tabular}{|c|c|c|c|c|c|c|c|c|c|}
\hline & \multicolumn{3}{|c|}{ BEKK } & \multicolumn{3}{|c|}{ DVEC } & \multicolumn{3}{|c|}{$\mathrm{CCC}$} \\
\hline & Coeff. & S.E. & z-Stat & Coeff. & S.E. & z-Stat & Coeff. & S.E. & z-Stat \\
\hline$M U(1)$ & -0.0001 & 0.0002 & -0.2416 & -0.0001 & 0.0002 & -0.3789 & -0.0001 & 0.0002 & -0.3406 \\
\hline$M U(2)$ & -0.0002 & 0.0006 & -0.3331 & -0.0002 & 0.0006 & -0.3662 & -0.0002 & 0.0006 & -0.4069 \\
\hline OMEGA(1) & 0.0016 & 0.0008 & 2.0002 & 0.0000 & 0.0000 & 1.3749 & 0.0000 & 0.0000 & 1.4123 \\
\hline BETA(1) & 0.8521 & 0.1414 & 6.0261 & 0.5346 & 0.2837 & 1.8848 & 0.4635 & 0.3172 & 1.4610 \\
\hline ALPHA(1) & 0.2340 & 0.0993 & 2.3559 & 0.1183 & 0.0751 & 1.5748 & 0.1430 & 0.0905 & 1.5798 \\
\hline OMEGA(2) & 0.0018 & 0.0007 & 2.5470 & 0.0000 & 0.0000 & 1.0459 & 0.0000 & 0.0000 & 4.4940 \\
\hline BETA(2) & 0.7506 & 0.1255 & 5.9801 & 0.4656 & 0.1721 & 2.7051 & 0.2638 & 0.1479 & 1.7840 \\
\hline ALPHA(2) & 0.3638 & 0.0729 & 4.9884 & 0.1709 & 0.0635 & 2.6903 & 0.2793 & 0.1124 & 2.4852 \\
\hline OMEGA(3) & 0.0042 & 0.0010 & 4.2815 & 0.0000 & 0.0000 & 2.7116 & - & - & - \\
\hline BETA(3) & - & - & - & 0.8899 & 0.0809 & 11.0067 & - & - & - \\
\hline ALPHA(3) & - & - & - & 0.0414 & 0.0282 & 1.4648 & - & - & - \\
\hline Log likelihood & \multicolumn{3}{|c|}{1926.456} & \multicolumn{3}{|c|}{1930.583} & \multicolumn{3}{|c|}{2366.001} \\
\hline Avg. log likelihood & \multicolumn{3}{|c|}{7.7680} & \multicolumn{3}{|c|}{7.7846} & \multicolumn{3}{|c|}{9.5403} \\
\hline Number of coeff. & \multicolumn{3}{|c|}{9} & \multicolumn{3}{|c|}{11} & \multicolumn{3}{|c|}{8} \\
\hline $\mathrm{AIC}$ & \multicolumn{3}{|c|}{-15.4634} & \multicolumn{3}{|c|}{-15.4805} & \multicolumn{3}{|c|}{-19.0161} \\
\hline SIC & \multicolumn{3}{|c|}{-15.3359} & \multicolumn{3}{|c|}{-15.3247} & \multicolumn{3}{|c|}{-18.9028} \\
\hline HQC & \multicolumn{3}{|c|}{-15.4120} & \multicolumn{3}{|c|}{-15.4178} & \multicolumn{3}{|c|}{-18.9705} \\
\hline
\end{tabular}

Table A3: Estimation results for the three bivariate models BEKK, DVEC, and CCC for log return series of BELEX15 index and Energoprojekt stock

\section{A.4. Trivariate case}

BEKK model
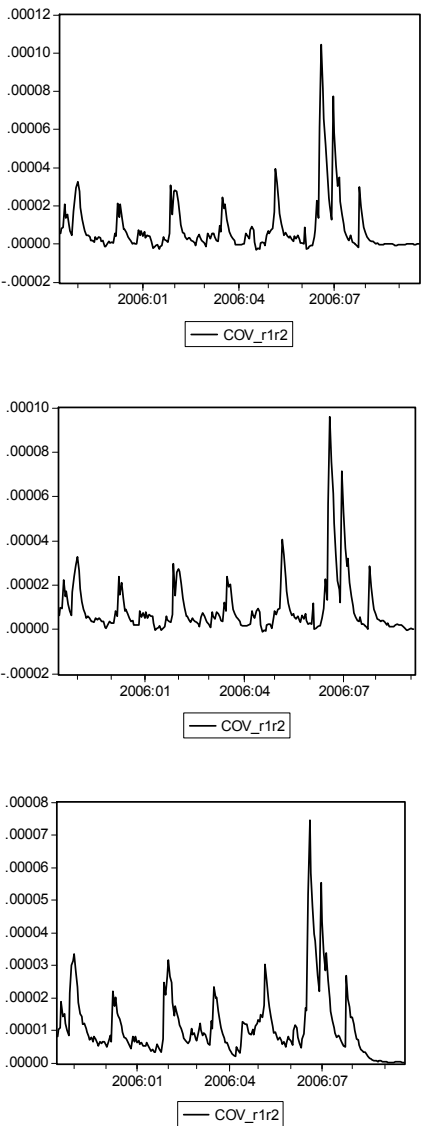

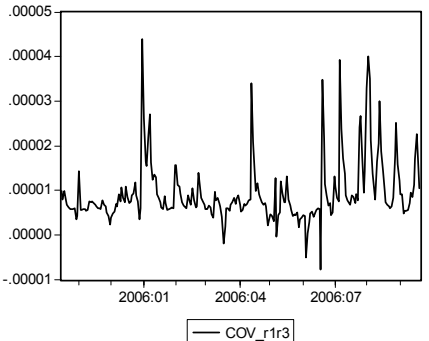

DVEC
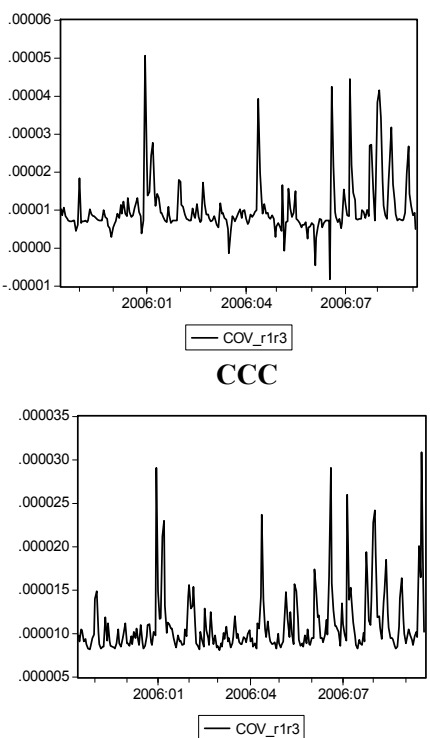
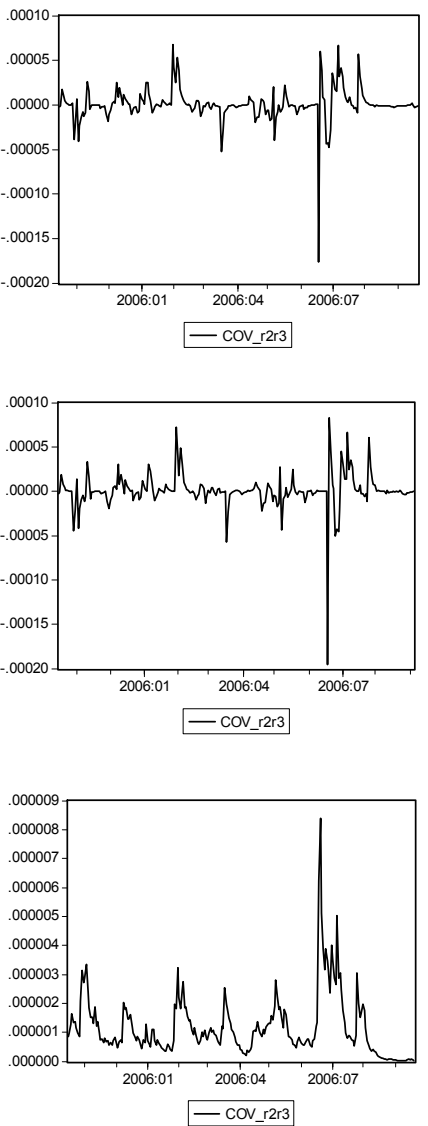

Figures A1: Estimated conditional covariances for daily log returns of BELEX15 index - Hemofarm stock (cov_r1r2); BELEX15 index Energoprojekt stock (cov_r1r3); Hemofarm - Energoprojekt stocks (cov_r2r3), respectively in restricted BEKK, DVEC and CCC models. 
BEKK
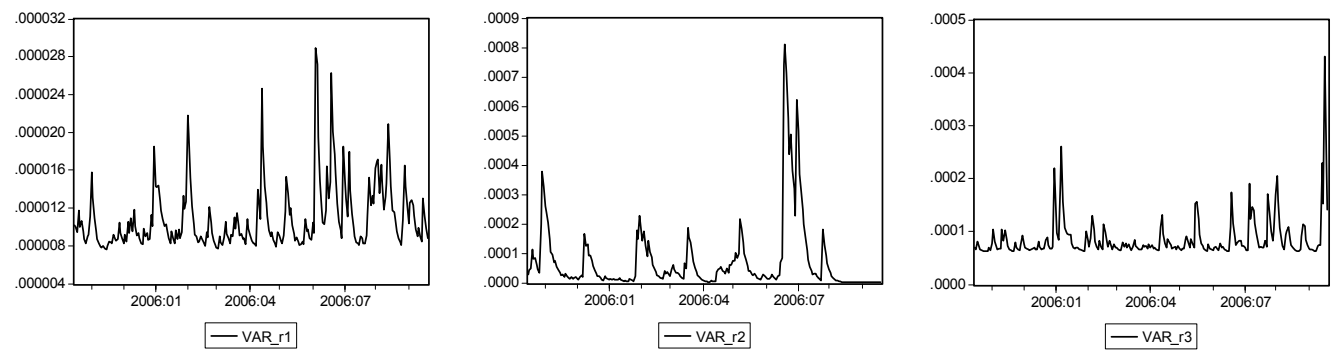

DVEC
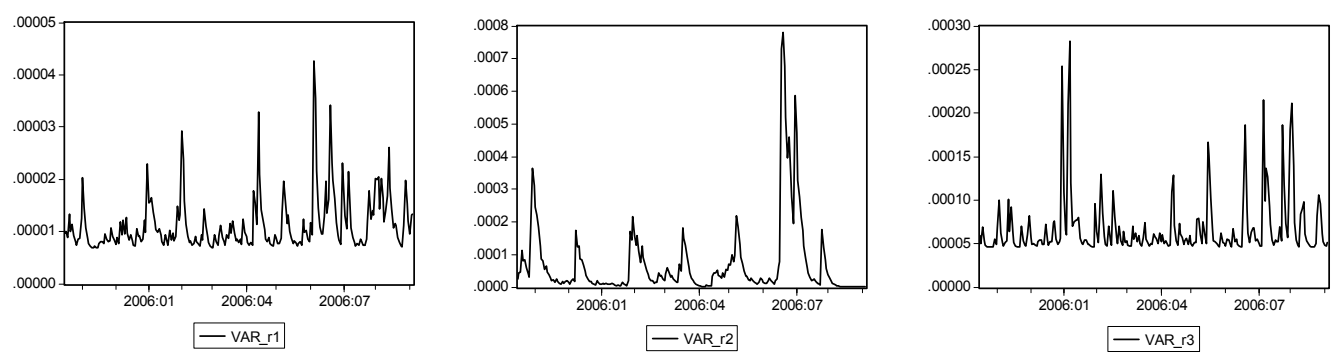

$\mathrm{CCC}$
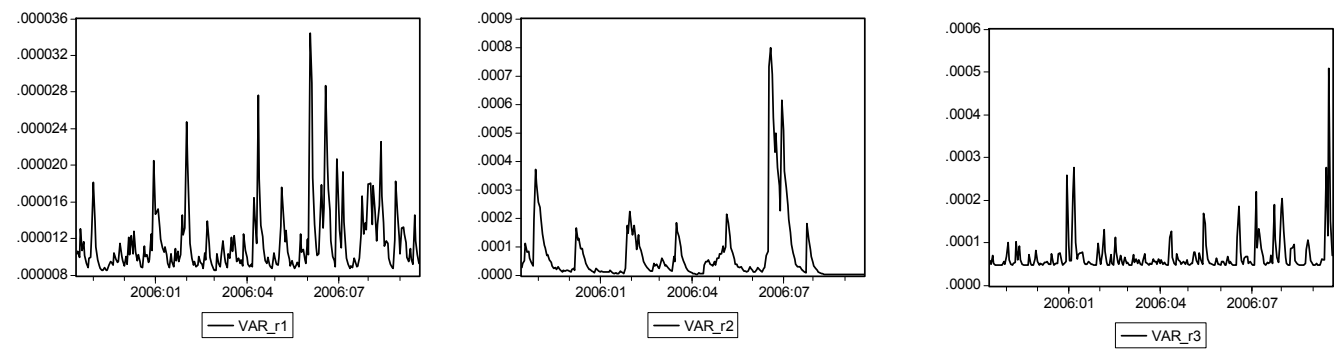

Figure A2: Estimated conditional variances of daily log returns on BELEX15 index (var_ $\left.r_{1}\right)$, Hemofarm stock (var_r $r_{2}$ ) and Energoprojekt stock (var_r $\left.r_{3}\right)$, respectively in the trivariate BEKK, DVEC and CCC models. 